\title{
A representação do trabalho em João Dias e Luís Bernardo Honwana
}

\author{
Rejane Vecchia da Rocha e Silva ${ }^{1}$ \\ Tatiane Reghini de Mattos ${ }^{2}$
}

A presente exposição pretende focalizar alguns aspectos observados em dois contos de escritores moçambicanos que se organizam, cada um a sua maneira, em torno do tema da força de trabalho (conceito fundamental para Marx e que propomos como chave para a análise crítica da ficção moçambicana). "Godido”, de João Dias, e “As mãos dos pretos”, de Luís Bernardo Honwana, são narrativas estruturadas a partir, principalmente, do questionamento de uma realidade social vigente e que, sendo assim, internalizam em suas composições aspectos fundamentais do contexto moçambicano sob os quais foram escritas. Dessa forma, apresentam, a partir de seus respectivos focos narrativos, em suas especificidades, conforme pretendemos discutir, as condições do trabalho do negro.

Nosso ponto de partida se organiza pela compreensão do que seja o trabalho, historicamente constituído dentro de uma ordem capitalista que inevitavelmente vai modificar as formas e relações de trabalho, no final do século Xix e século Xx, em territórios africanos com a ascensão dos colonialismos. Se no conto "Godido" isso se revela na dinâmica das relações estabelecidas entre o patrão Manuel Costa, a mãe de Godido e o próprio Godido, no conto "As mãos dos pretos", tais relações se manifestam a partir da compreensão da estrutura social que deixa clara a sua estratificação e a luta de classes que ali, dentro do modelo colonialista português em Moçambique, estabelecem-se. Seguindo algumas premissas marxianas, cujo repertório, sem dúvida, esclarece as intervenções do modelo capitalista em diferentes regiões do mundo dentro, portanto, de uma perspectiva ampliada, temos:

o trabalho, como criador de valores de uso, como trabalho útil, é indispensável à existência do homem - quaisquer que sejam as formas de sociedade -

1 Doutora em Letras e professora da Universidade de São Paulo (USP), São Paulo, sP, Brasil. E-mail: rejane.vecchia@gmail.com

2 Doutoranda no Programa de Estudos Comparados de Literaturas de Língua Portuguesa na Universidade de São Paulo (USP), São Paulo, sP, Brasil. E-mail: tatianereghini@gmail.com 
Rejane Vecchia da Rocha e Silva

TAtiane Reghini de Mattos

é necessidade natural e eterna de efetivar o intercâmbio material entre o homem e a natureza, e, portanto, de manter a vida humana (MARX, v. I, p. 5O, s/d).

Tomamos como pressuposto básico, portanto, os entrelaçamentos sempre dinâmicos entre a produção literária de um respectivo espaço, seu processo histórico específico e as relações socioculturais aí estabelecidas, para perceber nessa produção literária índices que revelam as conformações sociais que se desencadearam a partir da transformação das relações de trabalho. Procuramos, desse modo, refletir acerca das questões que se remetem à categoria do trabalho, e que compõem a tessitura literária, na medida em que, nos processos históricos vividos por Moçambique ao longo do colonialismo, o trabalho deixa de ser condição para uma existência social de acordo com os parâmetros endógenos historicamente, socialmente e culturalmente estabelecidos ao longo dos séculos, para se transformar em mercadoria, violência e estranhamento.

Sendo assim, faz-se importante a retomada da clássica e decantada diferença entre valor de uso e valor de troca, lembrando, primeiro, que o valor de uso sempre existiu na medida em que o homem, para suprir suas necessidades básicas, foi aprendendo a produzir bens necessários que garantissem a sua sobrevivência. E, em outra medida, encontramos o valor de troca que surge a partir de um excedente da produção e que vai tornando possível a troca dentro de uma curva ascendente, em que a produção em larga escala começará a projetar uma importante mudança em relação à constituição dos grupos sociais. Esses produzirão em escala cada vez maior, tornando inevitável um reajustamento das relações humanas dentro dessas estruturas sociais, sobretudo no que se refere à divisão social do trabalho e, depois, à divisão internacional do trabalho. Nessa relação constituída a partir do valor de troca emerge no sistema a mercadoria (cerne do capitalismo).

O que nos interessa, portanto, considerando as dinâmicas e dialéticas imbricações entre literatura e história, é perceber em que medida essas relações de trabalho impostas pelo capitalismo emergem na narrativa ficcional partindo das relações históricas de onde os contos de João Dias e Luís Bernardo Honwana emergiram. Destacamos, inicialmente, que a despeito da proclamação da República portuguesa, em 1910, em que se estabeleciam os ideais de liberdade, igualdade e fraternidade, o que permanecia paradoxalmente nas bases da ocupação dos territórios africanos era a 
A REPRESENTAÇÃo DO TRABALHO

EM JoÃo Dias E Luís BERnARDo Honwana

supremacia portuguesa, que tratava agora de regulamentar as novas formas de ocupação colonial efetivamente. De acordo com Maria Paula G. Meneses:

O dever moral de colonizar, de expandir os alcances civilizacionais da Europa ao resto do mundo era parte dos desafios das grandes nações, onde Portugal se incluía. "O império do mundo pertence às raças não somente mais activas, mas mais expansivas e colonizadoras”, afirmava Marnoco e Sousa (1910, p. 35). A diferença cultural assumia agora a tonalidade da diferença hierárquica racial, concepção desenvolvida a partir da articulação entre o evolucionismo, o positivismo e o racismo: "Raças não só diferentes, mas cientificamente inferiores à nossa [...], com um modo de pensar e de sentir proveniente é claro da sua organização social tão diversa, da sua própria organização física tão diferente, com uma moral e uma religião opostas até a nossa, absolutamente incapazes, cientificamente falando, de adaptar os seus cérebros rudimentares e de curto período de desenvolvimento, às nossas complicadas teorias e às nossas elevadas concepções" (Ornellas, 1903, p.13). A discussão sobre a "invenção" de África permite colocar em perspectiva a construção da Europa enquanto espaço distinto, cujo excepcionalismo justificava a sua missão messiânica de "salvar o mundo", o "fardo do homem branco" (KIPLING, 1899). O "fardo" acrescentava à missão política e científica da colonização uma dimensão moral, atribuindo à colonização uma racionalidade que procurava legitimar as intervenções imperiais em curso (MENESES, 2012, p. 74).

É possível perceber, portanto, as premissas legais que originariam normas e regras capazes de sintetizar e organizar juridicamente a exploração do trabalho negro, de acordo com os modos de produção capitalistas que se inscreviam nas dinâmicas sociais locais. Ainda segundo Maria Paula Meneses:

Os projectos de República para o desenvolvimento de Moçambique deram continuidade aos anteriores modelos de exploração do trabalho africano. Embora as críticas internacionais tenham levado a que o trabalho forçado fosse, juridicamente falando, abolido, em 1928, a legislação que se seguiu insistiria no dever moral do governo colonial em desenvolver as propensões morais dos indígenas encorajando-os a cumprir as suas obrigações morais de melhoria das suas condições de vida através do engajamento em actividades laborais compulsivas, durante seis meses por ano. Esta filosofia política colonial havia sido desenvolvida por um dos principais políticos coloniais, António Ennes. Em finais do século xix, o principal desafio que Portugal enfrentava era o de "obrigar as províncias ultramarinas a produzirem" (ENNEs, 1946, p. 27). Como nesta empresa não se poderia contar com o trabalho dos colonos brancos, sob argumento da inclemência do clima, da aridez do solo e da proliferação de doenças desconhecidas e insuportáveis, restava o trabalho 
Rejane Vecchia da Rocha e Silva

TAtiane Reghini de Mattos

indígena: precisamos dele para a economia da Europa e para o progresso da África. A nossa África tropical não se cultiva senão com africanos (MENEsEs, 2012, p. 75).

Desse modo, podemos inferir que as relações de trabalho estabelecidas, então, constroem a moderna escravidão, na medida em que os trabalhadores negros progressivamente perdem a posse da matéria-prima, dos instrumentos do seu trabalho e, consequentemente, do produto final - distanciando-se de seus modos de produção anteriores. E isso ocorre com a ascensão de sistemas colonialistas assentados em premissas de um capitalismo cada vez mais mundializado.

$\mathrm{Na}$ esteira dessa reflexão, para a qual esses movimentos do capital vão destituindo o homem de suas relações humanizadoras com o trabalho, é que se procura pensar acerca das incidências desses mecanismos e interesses econômicos e hegemônicos sobre as sociedades africanas desde a Conferência de Berlim (1884-1885), em finais do século XIX. Os colonialismos impuseram àquelas estruturas sociais mecanismos de intervenção capitalista, uma vez que a lógica político-econômica que todas as embarcações trouxeram na bagagem era o interesse exclusivo de acumulação de bens e riquezas para as respectivas metrópoles.

Essa seria, portanto, questão relevante trazida pela leitura dos textos de ficção e da produção poética de Moçambique. Para se pensar a questão da exploração da força do trabalho na realidade moçambicana, propomos aqui o recorte, a partir de dois contos já mencionados. Explica-se tal recorte, a princípio, pelo motivo mais óbvio relacionado às suas estruturas: ambos são contos e, portanto, uma história curta e fechada em si, em geral com uma só ação, um protagonista e um narrador objetivo. A seguir, por estarem ambos os contos de alguma forma ligados entre si por um aspecto fundamental: a percepção de duas crianças (protagonistas), sempre amparadas pela figura materna, sobre uma realidade relacionada à exploração da força de trabalho, que é conjecturada a partir do lugar do negro na esfera do trabalho em Moçambique no período da colonização.

Há no livro de contos Godido e outros contos, de João Dias e Nós matamos o cão tinhoso, de Luís Bernardo Honwana, aspectos fundamentais relativos às suas estruturas narrativas que indicam, no percurso de sua construção, o interesse comum de trazer como eixo central as tensões sociais do país, que 
A REPRESENTAÇÃO DO TRABALHO

mobilizaram a ação de tantos escritores, sobretudo a partir da década de 1940, em países africanos (não só de língua portuguesa). Ressaltamos que os dois contos aqui apresentados trazem em comum uma dinâmica de denúncia ora mais evidente por um narrador irônico e ora mais escamoteada por um narrador infantil, mas ambos imbuídos pelo contagiante interesse de entender o espaço social dentro do qual circulam e que se organiza, sobretudo, a partir da depreciada relação de trabalho estabelecida entre proprietários brancos e empregados negros.

Em João Dias, nascido em 1926, são relevantes a intensidade narrativa, marcada por uma gradação que se observa através dos olhos de Godido em relação ao espaço físico dentro do qual se encontra, o latifúndio de Manuel Costa, e a densidade com que projeta as suas personagens num cenário de opressão sistemática em que crianças, mulheres e homens de todas as idades se encontram enredados na dinâmica de um moderno modelo ${ }^{3}$ de escravidão. Mas, para além da intensidade projetada por essas muitas personagens, a comoção se reforça quando descobrimos, no caso de João Dias, que o autor dessas imagens faleceu aos 23 anos e que, portanto, sua escrita está embebida na profundidade dos argumentos constituídos a partir de uma compreensão urgente do processo histórico, que impunha àquelas populações uma realidade violenta de exploração.

Seu emblemático conto "Godido" desencadeia uma sequência de imagens em que a realidade da opressão colonialista revela-se a partir da chegada do português-patrão Manuel Costa, que traz consigo "máquinas, autoridade, réguas" (DiAs, 1988, p. 35). A chegada de Manuel Costa anuncia, assim, as transformações do local, essencialmente no que se refere à esfera do trabalho, como podemos identificar na explicação do narrador:

Os pretos dividiam-se em dois grupos: os das pequenas machambas independentes e os empregados da quinta. Os primeiros, sentindo o peso dos impostos, vendiam seus produtos ao caseiro. De modo que uns subordinados

"A linguagem que atravessa a missão civilizadora [portuguesa] estava pois profundamente imbuída de princípios racistas. Nos modernos contextos coloniais, de que Moçambique foi exemplo, os negros 'não civilizados' ou indígenas eram considerados meros súditos coloniais, podendo ser recrutados pelas autoridades coloniais para o trabalho forçado" (MoNDLANE, 1995). A metáfora estruturadora destas relações no espaço colonial era a noção de civilizado, que rapidamente se transformou em sinônimo de europeu, a que se opunha a imagem dos colonizados, simbolizados pelo indígena africano. $\mathrm{O}$ 'não-indígena' original detinha, teoricamente, todos os privilégios da cidadania portuguesa” (MENESES, 2012, p. 83). 
Rejane Vecchia da Rocha e Silva

TAtiane Reghini de Mattos

diretamente e outros conscientes de uma liberdade que não tinham, todos viviam para o grande proprietário (DiAs, 1988, p. 35).

A partir daí, o cotidiano é transformado pelas leis que vão garantir o enriquecimento do novo proprietário. Tomada a terra, transformada parte significativa da mão de obra em trabalho alienado, endividada a outra parte pelos altos impostos cobrados, o espaço é violentamente atingido por novas regras e leis que, de forma progressiva, irão empobrecer as condições de vida daquela população. $\mathrm{O}$ foco narrativo onisciente e em terceira pessoa, que abre espaço para o desencadeamento do discurso direto livre, revela uma aflitiva projeção de um mundo mobilizado pela produção e acumulação de riquezas, no qual a força de trabalho está posta como mercadoria, e é convertida em lucro para branco e em expropriação para o negro.

O conto é construído a partir de um movimento dialético que se organiza materialmente no plano da escrita de duas maneiras: à medida que o fortalecimento de Manuel Costa significa o empobrecimento da população e à medida que o amadurecimento de Godido, que busca sua emancipação, implica em um menor espaço para a exposição das conquistas de Manuel Costa no conto. Organiza-se a estrutura narrativa, portanto, a partir da ascensão econômica e social do patrão em oposição às precárias condições sociais das populações locais, que perdem seus direitos e são encerradas em um projeto jurídico-social que legitima a mão de obra compulsória, na primeira parte. Mas também, em seu inverso, na segunda parte, organiza-se através da resistência de Godido a essa condição, impulsionada, principalmente, pela consciência emancipadora de sua mãe.

Temos então que o conto se inicia remetendo-se àquilo que poderia ser entendido como o princípio de um conto de fadas, "Era uma vêgi um dia." ([Era uma vez...] Dias, 1988, p. 35). Se por um lado, temos uma posição tanto quanto irônica colocada aqui na narrativa, uma vez que em uma história de cunho denunciativo de uma realidade de invasão e exploração sobrepõe-se um início que remete inevitavelmente ao aparato ideológico dos contos de fadas (sobretudo os propagados por Walt Disney nas primeiras décadas do século $\mathrm{xx}$ - com direito a princesas, castelos, bruxas e madrastas e finais felizes), por outro, temos uma subversão desse aparato através da projeção de uma voz moçambicana (com acentuados registros de coloquialidade), que se põe a contar sobre o seu lugar e a condição que lhe foi dada no mundo. 
A REPRESENTAÇÃo DO TRABALHO

EM JoÃo Dias E Luís BERnARDo HonwanA

Bettelheim, um dos grandes pesquisadores de conto de fadas, afirma que:

Os contos de fadas, diferentes de qualquer outra forma de literatura, dirigem a criança para a descoberta de sua identidade e comunicação, e também sugerem as experiências que são necessárias para desenvolver ainda mais o seu caráter. Os contos de fadas declaram que uma vida compensadora e boa está ao alcance da pessoa apesar da adversidade - mas apenas se ela não se intimidar com as lutas do destino, sem as quais nunca se adquire verdadeira identidade (Bettelheim, 1980, p. 32).

Ainda, segundo o autor, o conto de fadas refere-se, sempre, ao mundo interior mais do que ao mundo exterior, embora possa apresentar-se "de forma bastante realista e ter entrelaçados os fatos do cotidiano" (198o, p. 33). Refletindo acerca dessas considerações de Bettelheim, podemos dizer que no imediato do conto de João Dias somos remetidos então para uma espécie de tomada de voz moçambicana que norteará a construção do enredo, encaminhando o protagonista para a construção de sua identidade a partir da ruptura com um destino (mundo interior) que desde o nascimento lhe é imposto pela realidade colonial (mundo exterior). Para isso colabora, como podemos observar, o caráter denunciativo que será o principal aporte da voz narrativa: "Agora machamba não é de preto" (DiAs, 1988, p. 35). Mais que isso, também colabora a construção no conto de uma condição de trabalho adversa que precisa ser superada para que Godido alcance uma vida "compensadora e boa" (ao menos, livre).

É sob essa expectativa criada ao longo de toda a primeira metade do conto que emerge a figura de Godido. Temos então que, desde o nascimento, sua condição de vida é submetida às opressivas relações de trabalho presentes naquele espaço de domínio do "senhor Costa", o que já estava cunhado na narrativa pelo ponto de vista do narrador, que evidentemente (pela ironia) opõe-se à ascensão de Costa, e será ressaltado no dia do nascimento de Godido, relativamente ao dia de trabalho de sua mãe, dona Carlota: "Certo dia sentiu náuseas, voltou à palhota. Descontaram-lhe horas de trabalho. A barriga rompeu e vazou. O senhor Costa espiou" (DiAs, 1988, p. 36).

É importante notar que a presença de Godido no conto acontece, portanto, após a elaboração de um primeiro momento do movimento dialético, ao qual fizemos menção inicialmente, com um senhor Manuel Costa atingindo o ápice de seu poder, porque já havia tomado o lugar do soba, fazendo-se "de juiz entre 
os indígenas", expulsado o feiticeiro, "raivando riso, empurrou pra longe o negro ladrão", e colocando-se, portanto, como patrão e máxima autoridade local.

Em oposição à ascensão de Manuel Costa, intercalando a ocupação do território (que se quisermos, podemos entender como país metonimicamente representado por essa aldeia), as diversas passagens que compõem o discurso direto livre auxiliam o narrador a alertar para a falta de liberdade, o pagamento forçado dos impostos, a fome, o excesso de trabalho, a falta da escola, numa cadência que configura a situação de exploração, culminando numa desigualdade que se assenta sobre a fome e não tolera possibilidades futuras: "Os produtos seguiam para as grandes cidades. Na aldeia, a fome" (DiAs, 1988, p. 35); "Escola pra preto num tinha. Branco estava a falar cos pretos é só pra cavari, cavari ni chão" (DIAs, 1988, p. 36). É a partir desse contexto, assim projetado nessa unidade sempre contraditória entre proprietário e trabalhador, entre os donos dos meios de produção e a força de trabalho, entre o colonialista e as populações locais, organizadas parágrafo a parágrafo até aqui, que se dará início da segunda parte do conto (marcada pela percepção da mãe sobre os quinze anos do filho), em que a fuga de Godido em busca de sua liberdade torna-se o centro da narrativa. O que ocorre é uma espécie de virada narrativa: conforme Godido ascende como herói (aprontando-se para as lutas do destino, ou seja, sua fuga àquele destino que lhe está sendo imposto), Manuel Costa sofre uma espécie de apagamento no conto, enquanto personagem que pratica ação, para tornar-se apenas um referencial negativo (representado através da onisciência do narrador que acompanha Godido).

Para essa virada, no entanto, apresenta-se como fundamental o despertar de Dona Carlota para uma resistência ainda a ser organizada (e que organiza a resistência de seu filho). A exploração do trabalho e as violações sexuais praticadas pelo patrão, colocam a mãe de Godido num posicionamento que dissolve qualquer defesa do ponto de vista lusotropicalista e, com isso, a personagem também se desloca para o campo das denúncias, em que já está o narrador e para o qual está projetada a ação de Godido, para anunciar a sua resistência às condições de opressão, dentro das quais ela e o filho se encontram. A vida "é mais que mandioca e chicote" (DiAs, 1988, p. 37) é o que dirá ao filho, e "Godido ficou maluco... fugiu" (DiAs, 1988, p. 37) será sua 
A REPRESENTAÇÃo DO TRABALHO

resposta intencionalmente evasiva ao patrão. Fortalece, à sua maneira, a premissa de que as potencialidades futuras, segundo Ernest Bloch, surgem na experiência cotidiana, ou como defende:

A esperança sabedora e concreta, portanto, é a que irrompe subjetivamente com mais força contra o medo, a que objetivamente leva com mais habilidade à interrupção causal dos conteúdos do medo, junto com a insatisfação manifesta que faz parte da esperança, porque ambas brotam do não à carência (BLOCH, 2005, p. 15-16).

Dona Carlota assume, assim, o ponto de vista próximo ao narrador que desde o início se revela por meio de digressões organizadas ao longo do conto: "A vida fazia-se fábrica de descasque: os homens entravam, descascavam-se e saíam farelo para a estrumeira" (DiAs, 1988, p. 36); ou "Na máquina ficava suor. Amadureciam os campos, desfazia-se a vida em adubo. Não se pintavam novas cores no cenário; era aquele o método único, com mais ou menos pormenores" (DiAs, 1988, p. 36) Nesse fluxo composto por uma voz narrativa que abre espaços para o discurso de variadas vozes, é possível perceber, sobretudo, uma intenção política, uma estratégia discursiva que assim construída aproxima o narrador de d. Carlota e de Godido.

Há, portanto, no conto uma ruptura subversiva que emerge dentro da própria estrutura colonialista na medida em que será dona Carlota, por exemplo, a responsável pela partida do filho menino que começa a amadurecer.

Mamana Carlota lembrou que tinham passado tantos anos quantos os dedos das mãos e de um pé, depois que Godido nascera. Cercavam-no olhos brancos de cobiça do senhor Costa, gulavam-lhe charruas e sementeiras no campo. Mãe negra desgastara-se naquilo; sabia os trabalhos dos que nem corpo haviam para a sexualidade do senhor Costa. Godido precisava outros rumos (DiAs, 1988, p. 36-37).

A recusa de dona Carlota daquela realidade revela não só o potencial de subversão, como a capacidade de intervenção inscritas dentro de uma realidade silenciada pela exploração do trabalho através de um colonialismo com amparo militar. Assim, Godido inicialmente entre ir e não ir (às lutas do destino), acaba deparando-se com a fronteira da cidade. Ainda que a cidade pareça trazer nos finais do conto a reprodução da configuração das cercanias do Senhor Costa (o sistema colonial é o mesmo), fica evidente, na voz do narrador, que o seu lugar de liberdade só poderá ocorrer a partir da resistência a um sistema que lhe é massacrante: "Como se não fosse humano um negro pensar que a 'vida 
do negro há-de acabar'” (p. 38). Há, portanto, nessa estruturação, o despertar do menino de 15 anos para uma vida que lhe é imposta por ser negro e para a necessidade de busca de novos horizontes.

Para confirmar essas impressões vale lembrar o poema de Noémia de Souza, escrito em 1950, em homenagem a João Dias:

Dos longes do meu sertão natal / eu desci à cidade da civilização.

Quando cheguei, / trazia no olhar a luz verde dos negros simples / e uma dádiva maravilhosa em cada mão.

Mas a cidade, a cidade, a cidade! / Esmagou com os pneus do seu luxo, / sem caridade, / meus pés cortados nos trilhos duros do sertão. / Encarcerou-me numa neblina quase palpável de ódio e desprezo, /

exigiu-me impiedosamente a abdicação / da minha qualidade intangível de ser humano! /

Nas noites frias, / sem batuque, / sem lua, / as estrelas continuaram brilhando, insensíveis,/ através da cacimba, suspensas dos postes da rua. / Minha consolação: / Minha Mãe silenciosa oferecendo-me suas costas nuas, / mornas como sol de inverno.../ minha Mãe vencendo a cacimba e a solidão, / para me vir belekar, / humilde e sofredora, com suas tocantes canções de acalentar!

Ah, mas eu não me deixei adormecer! / Levantei-me e gritei contra a noite sem lua, / sem batuque, sem nada que me falasse da minha África, / da sua beleza majestosa e natural, / sem uma única gota de sua magia! / A luz verde incendiou-se no meu olhar / e foi fogueira vermelha na noite fria / dos revoltados.

ainda grito,/ porque quero ser ainda, sempre, pela vida fora, / o que fui outrora: / Rainha nas costas de minha Mãe!

Por isso é que este meu canto ingênuo que soa banal, / traz no seu fundo mais fundo, Godido, meu irmão / a marca rubra dum selo fraternal, / constante e imortal! (SousA, 2001, p. 130).

A justa homenagem de Noémia de Sousa a João Dias resgata o vigor de suas reflexões, que se organizam por meio de uma escrita literária contundente e que acenam para a organização dos movimentos sociais politicamente e subversivamente engendrados nos subterrâneos do colonialismo, sinalizando as potenciais (e complexas) guerras de libertação a caminho. Conto e poema reclamam não só pelos espaços ocupados, pela condição dentro da qual suas populações se encontram mas registram, sobretudo, o desejo da ação, uma militância que nos parâmetros da escrita se constitui também. Emerge dessa 
A REPRESENTAÇÃo DO TRABALHO

escrita literária um potencial sujeito coletivo, à medida exata de um projeto político em construção e de um movimento revolucionário a caminho. Noémia de Sousa recorre ao vocábulo "fraternal", mais uma vez, vocábulo essencial em sua produção poética, abarcando o contexto sob a perspectiva endógena para tratar não só da irmandade que se deve projetar a partir da opressão colonialista mas, principalmente, uma irmandade produtiva, porque a partir dela a luta precisa ser organizada. A tônica da contestação de João Dias encontra na poesia de Noémia interlocução e sentido.

Valeria recorrer às reflexões de Raymond Williams no que diz respeito à produção cultural, definindo-a como um espaço social e histórico das práticas sociais, materiais e simbólicas. Espaço e instância de dominação, mas, também, esfera de realizações, sendo, ao mesmo tempo, produto e produção de um modo de vida em um determinado momento histórico. Comum, ordinária, encravada no modo de vida da experiência cotidiana, como uma forma de se pensar o que organiza a sociedade. No entanto, no embate das relações colonialistas, o espaço não é de todos e as experiências cotidianas concentramse na divisão desigual das riquezas e do trabalho. O conto de João Dias registra a produção de outros sentidos, significados e valores, permitindo ao leitor a apreensão das relações sociais estabelecidas sob o prisma endógeno, mas que vão apontar para uma tentativa de descortinar a natureza do colonialismo e as implicadas relações sociais estabelecidas, além de sua complexidade. A literatura surge nesse cenário como chave para a compreensão do funcionamento social e sua potencial transformação.

Em consonância com o conto de João Dias, "As mãos dos pretos" volta-se também para a realidade do país, procurando dissecar as relações estabelecidas dentro da estrutura do poder colonial. Em comum com Godido, apresenta a complexa realidade das condições de trabalho, percebida a partir do olhar infantil que acaba imprimindo uma possibilidade de resistência, como pretendemos demonstrar.

Embora escrito em 1964, portanto cerca de quinze anos depois de "Godido", o conto de Honwana também aponta para a aguda desigualdade social presente no país, que a esta altura inicia a sua luta de libertação. No entanto, é a curiosidade de uma criança revelada não negra desde o início do conto ("até os pretos eram melhores do que nós"), que serve de mote para que os aparelhos repressivos e ideológicos do Estado Português, seguindo a conceituação 
proposta por Althusser, sejam apresentados a partir da realidade daquele momento moçambicano. O conto é narrado pela voz em primeira pessoa desse garoto, que tem dúvida sobre o porquê da cor das palmas das mãos dos negros não serem negras como o restante de seus corpos.

A partir dessa indagação, aguçada na criança pelo Senhor Professor - e valeria destacar, uma indagação carregada de intenção, afinal, o espaço da escola é um dos mais importantes mediadores ideológicos entre o indivíduo e a sociedade -, ela passará a circular pelo universo dos adultos (brancos, como notamos), em busca de uma resposta que contemple sua dúvida. No entanto, as respostas que encontra nas instituições às quais recorre, pelas quais circula com liberdade e que constituem o aparelho ideológico do estado português no sistema colonial, instituições ali metonimicamente representadas por aquelas personagens inscritas nesse universo colonialista, não lhe suprem a dúvida, sendo insuficientes. São respostas que se elaboram, sobretudo, a partir da conjugação entre um campo de força ideológico essencial que é o da religião e pelas relações de trabalho impostas, elementos essenciais para a formação de um imaginário em que é latente a intenção declarada e objetiva de construir e fortalecer uma imagem inferiorizada do negro.

Numa sequência cadenciada pelos parágrafos, encontramos essas respostas e constatamos, com o narrador-menino, aquilo que nelas é inerente ao racismo e à exploração perpetuada numa sociedade colonizada. O Professor (escola) é o primeiro a afirmar que os negros teriam as palmas das mãos brancas porque andavam há poucos séculos apoiados no chão, "como os bichos do mato" (HonwanA, 1980, p. 75). Já o Senhor Padre (igreja) afirma que é porque andavam às escondidas sempre a rezar; a Dona Dores (família) diz que é para não sujarem as comidas que cozinham para os patrões ou as atividades de limpeza que lhes mandam realizar. O Senhor Antunes da Coca-Cola (símbolo emblemático do capitalismo hegemônico), por sua vez, conta ao menino que Jesus, Maria e São Pedro fizeram os pretos nas chaminés e que, portanto, foram coloridos pelo fumo, pendurados pelas mãos, que assim permaneceram brancas. Insatisfeito com essas respostas, na contramão do senhor Antunes e de todos os senhores que "desataram a rir, todos satisfeitos” (HonWANA, 1980, p. 76), o menino escuta a explicação do Senhor Frias, que lhe diz que se eram assim isso se explicava pelo fato de não terem se lavado por completo no lago do céu. 
A REPRESENTAÇÃo DO TRABALHO

Inconformado, ainda, o menino se lembra de um livro em que encontra uma outra explicação de que os negros tinham as mãos assim "por viverem encurvados sempre a apanhar o algodão branco de Virgínia e de mais não sei onde" (HonwAnA, 1980, p. 76). É importante notarmos que, embora a resposta do livro não seja completamente convincente ao menino, ela apresenta a questão do trabalho forçado, pois que "vivem curvados a apanhar o algodão" introduz a questão do trabalho na Virgínia, expandindo o problema para além das fronteiras do país, portanto, para um campo de visão ainda maior (nota-se que Virgínia é um estado estadunidense reconhecido tanto pelas revoltas de negros contra a escravatura quanto por sua sociedade conservadora e escravocrata). Dessa forma, nesse momento narrativo, cria-se uma tensão de perspectiva crítica, que problematiza a explicação dada pelo professor, colocando, portanto, em conflito dois importantes referenciais de conhecimento (livro e professor).

Ao acenar para essa nova perspectiva, a resposta do livro embute no menino uma espécie de atenção cuidadosa para a ambiguidade manifesta entre as duas respostas. Embora as duas estejam atreladas ao preconceito racista, a informação do professor se estrutura a partir de uma falsa teoria evolucionista, enquanto as informações inscritas no livro, que chegam tangencialmente ao conhecimento do menino, na medida em que o livro "por acaso falava nisso", imputam ao trabalho a problemática levantada (HoNWANA, 1980, p. 76). É possível perceber, portanto, a ascensão cada vez mais acentuada de uma espécie de inconformismo do menino com relação às explicações dadas, uma vez que nenhuma delas oferece consistência ou algum índice de plausibilidade. Dona Estefânia, refuta a afirmação encontrada no livro e para o menino isso fica claro, no entanto, também ela não está fora do eixo das perspectivas colonialistas, pois explica ao menino que as palmas das mãos são brancas “à força de tão lavadas”, cuja mensagem subliminar, é possível inferir, vem do fato de que se não forem obrigados, não as lavarão.

A pergunta feita reincidentemente pelo menino para essas diversas personagens insere nele uma percepção daquela realidade que expande gradativamente a sua compreensão do espaço social e a ideia do embate entre classes sociais distintas, a colonialista e a trabalhadora. Essa percepção, portanto, inevitavelmente emerge na narrativa e se organiza a partir do caminho percorrido pelo menino, que começa no professor e deste ao padre, 
e deste à Dona Dores, e desta ao Senhor Antunes, e deste ao Senhor Frias e, finalmente, à Dona Estefânia, encerrando uma espécie de ciclo que se renovará com a resposta que virá da mãe, introduzida na seguinte passagem: "A minha mãe deve ser a única que deve ter razão sobre essa questão de as mãos de um preto serem mais claras do que o resto do corpo" (HonWANA, 198o, p. 77).

Esse embate, portanto, está posto e se revela na narrativa pela teimosia do menino em não acatar as respostas ouvidas, resultado de sua própria observação do meio social: servindo aos patrões, está, justamente, o trabalhador negro, pressuposto necessariamente dado. Esse indivíduo invisível no cenário que se configura em primeiro plano é o que alimenta a contestação do menino manifesta em sua dificuldade em aceitar as explicações até ali oferecidas, daí a sua teimosia. Na narrativa que se condensa entre o professor e Dona Estefânia, as explicações estão pautadas pelo divino (foi assim porque tinha que ser segundo uma esfera não dominada pelo homem) e/ou pelo trabalho (porque tinha que servir aos brancos), sob uma perspectiva claramente calcada na mentalidade colonial, em que vigora a ideia de inferioridade que abaliza o trabalho compulsório, mas que não convencem o menino, despertando sua desconfiança ao que está institucionalizado.

A elaboração de uma possibilidade de resistência a essa institucionalização da mentalidade colonial se solidifica na estrutura narrativa quando, ao final do conto, a resposta de sua mãe lhe convence, embora, como veremos, apresente atitude que ainda o confunda.

Deus fez os pretos porque os tinha de haver. Tinha de os haver, meu filho, Ele pensou que realmente tinha de o haver... Depois arrependeu-se de os ter feito porque os outros homens se riam deles e levavam-nos para as casas deles para os pôr a servir como escravos ou pouco mais. [...] Pois olha: foi para mostrar que o que os homens fazem, é apenas obra dos homens... Que o que os homens fazem é feito por mãos iguais, mãos de pessoas que, se tiverem juízo, sabem que antes de serem qualquer outra coisa são homens (HonwANA, 1980, p. 77, grifo nosso).

Na exposição de que "o que os homens fazem, é apenas obras dos homens", a divisão do trabalho é retratada, no conto, como resultado histórico das decisões e dos interesses estabelecidos por determinados homens. Com a pista revelada por aquela perspectiva do livro associada a esta perspectiva materna, o que emerge, com ênfase, é a substancial chave do conto: os homens são responsáveis pelas suas ações e escolhas, e, dessa maneira, aqueles que se 
A REPRESENTAÇÃo DO TRABALHO

instalaram no centro do poder, através de suas ideologias opressivas calcadas no racismo e na exploração da força de trabalho não encontram, na maturação desse menino-narrador, espaço para se perpetuarem - pelo contrário, encontram resistência. A realidade que vai sendo retratada através das respostas encaminha o menino, nas entrelinhas do conto, para o questionamento dessa ordem dada. E acaba por fortalecer nele o ponto de vista de sua mãe: "A minha mãe é a única que deve ter razão sobre essa questão" (HonwANA, 1980, p. 77).

O menino, que só pode observar o mundo a partir da infância, portanto, sem uma experiência histórica mais ampliada, não parece entender claramente as reações da mãe, que aciona no texto a contradição social dialeticamente constituída a partir de sua compreensão do que sejam e de como se estabeleçam as relações sociais diametralmente opostas dentro do colonialismo (seu referencial e ponto de partida). Temos, primeiro, "No dia em que falamos nisso, eu e ela, estava-lhe eu ainda a contar o que já sabia dessa questão e ela já estava farta de se rir" (HonwANA, 198o, p. 77), mais adiante:

O que achei esquisito foi que ela não me dissesse logo o que pensava disso tudo, quando eu quis saber, e só tivesse respondido depois de se fartar de ver que eu não me cansava de insistir sobre a coisa, e mesmo assim a chorar, agarrada à barriga como quem não pode mais de tanto rir (HoNWANA, 1980, p. 77).

E a seguir, "nunca tinha visto uma pessoa a chorar tanto sem que ninguém lhe tivesse batido" (HonwanA, 198o, p. 77). A informação inicial fornecida pelo conto a respeito da inserção social do menino é a de sua permissão para circular no mundo colonialista (sabemos que o menino não é negro). Concomitantemente a sua impossibilidade de aceitar as explicações anteriores e agora confrontadas com as explicações da mãe, potencializa-se na sua experiência da infância por meio de uma percepção que emerge de sua experiência histórica e, portanto, material da vida aliada à experiência de sua mãe, talvez uma trabalhadora negra, o que não fica claro na narrativa (mas torna-se uma hipótese pelo pronome "nos" em "levavamnos para sua casa”). Portanto, a sua permissão para transitar no espaço social e físico colonialista ascenderia na dimensão das condições de um menino mestiço. Assim, a sua possibilidade de observar o mundo a partir dos parâmetros do mundo do trabalho alienado é desencadeada também pela 
Rejane Vecchia da Rocha e Silva

TAtiane Reghini de Mattos

figura materna, como também acontece em Godido, em que a mãe é essa consciência antecipatória de um desejo de emancipação social.

No entanto, o menino-narrador (que ao longo do conto tece a compreensão das relações sociais postas, como um narrador em primeira pessoa, observador) carrega consigo o que é próprio dessa sensibilidade infantil, que percebe de maneira limitada a complexidade das relações humanas. Mas o fato é que a resposta satisfatória dada por sua mãe revela uma dimensão de panorama futuro que, apesar de complexo, parece apontar para a possibilidade de um outro horizonte - com relações mais iguais, - tão consonantes aos anseios do tempo em que o conto foi escrito. O que é evidenciado na sua dificuldade em aceitar a explicação dos demais em oposição à explicação de sua mãe reside no fato de que, sob seu ponto de vista, dado a partir de determinada conjuntura local, acatar a perspectiva colonialista que infere ao negro inferioridade, colocando-o a mercê do trabalho forçado, não é possível.

Deus fez os pretos porque tinha de os haver. [...] Depois arrependeu-se de os ter feito porque os outros homens se riam deles e levavam-nos para as casas deles para os pôr a servir como escravos ou pouco mais (HoNWANA, 198o, p. 77).

Godido e o menino-narrador estão, possivelmente, inseridos em lados distintos de uma realidade social, mas compartilham de uma mesma perspectiva prospectiva de resistência, a partir da perplexidade diante da realidade opressiva do país. Enquanto Godido está do lado dos oprimidos pelo sistema colonial, o menino-narrador circula bem pelo lado dos opressores. No entanto, as ações de ambos estão projetadas para uma mesma questão: o lugar do negro na sociedade colonial e as suas condições de trabalho. O narrador de Godido projeta, ao longo da narrativa, a sua resistência, o narrador-menino de "As mãos dos pretos" resiste diante de respostas que deveriam ser, para alguém que circula pelo espaço privilegiado na sociedade colonial, facilmente aceitas e satisfatórias. O trabalho é um ponto chave nessa realidade e assume papel central para o entendimento dessas resistências: se Godido precisa resistir às explorações e às condições de trabalho as quais seria submetido pelo Costa, em "As Mãos dos Pretos", pelo contrário, o menino educado institucionalmente para praticar essa exploração começa também a questioná-la. As figuras maternas nos dois contos são os eixos condutores da consciência dessa necessidade de resistência: as mães direcionam seus filhos para novos caminhos, com novos horizontes. 
A REPRESENTAÇÃo DO TRABALHO

As estruturas dos dois contos aqui analisados revelam paulatinamente as ideias que se sobressaem de uma sociedade condenada à colonização, na qual os valores que emergem, os hegemônicos, são sempre os daqueles que estão no poder, ou seja, os colonizadores. Exibindo essa realidade implausível de opressão e exploração acabam por colocá-la em xeque, projetando suas personagens, tanto de um lado quanto de outro, para a resistência.

Será que se requer grande acuidade de espírito para se compreender que ideias, noções, concepções, numa palavra, a consciência do ser humano sofre modificações em função das mudanças que operam nas condições concretas de sua existência material, em suas relações sociais, em sua vida social?

Não é isso que a história das ideias confirma, que a cultura se modifica na medida em que se modifica a produção material? As ideias dominantes de uma época sempre foram as ideias da classe dominante.

Falar em revolucionar uma sociedade significa que, no bojo mesmo da velha sociedade, formaram-se elementos de uma nova sociedade e que a queda de velhos conceitos acompanham a queda das antigas condições de vida (MARX; Engels, p. 34, 1986).

Os textos literários anunciam, engendram, reclamam as contradições resultantes dessa ordem capitalista estabelecida, encenando os embates travados na esfera social, e as diversas formas de ser e de estar no mundo pelas práticas sociais vividas. A partir da transformação dessas crianças, lançam, sobretudo, o olhar para a potencial transformação social que vem da autonomia crítica da consciência humana, gerada no embate entre as estruturas do poder e a experiência cotidiana da exploração.

Notamos que ambos os contos analisados convergem para o questionamento da ordem dada, da situação de exploração presente e de uma possível nova possibilidade de futuro. Se há diferenças substanciais que tingem suas estruturas, tanto com relação à voz narrativa, quanto com relação à explicitação da temática que propõem como discussão e à projeção do protagonista, é necessário que coloquemos em nossa perspectiva de análise o contexto histórico disposto nos textos. Em João Dias era urgente a revelação da condição precária de exploração imposta aos negros naquela década de 1940, em que os autores se posicionavam politicamente na literatura com o intuito de dar voz aos Godidos amordaçados. Para Honwana, além disso, ao escolher um narrador infantil não negro, parece ser fundamental também pontuar as 
complexidades impostas por aquele universo colonial, que persistirão à luta de libertação. No entanto, também é perceptível, como esta análise procurou apontar, que ambos os textos denunciam, cada um à sua maneira, as relações de trabalho e de exploração presentes na sociedade moçambicana nos tempos da colonização, que despertam a consciência do menino Godido e do meninonarrador perante a realidade que se apresenta, elaborando neles um ímpeto de resistência.

Se o longo período que se estende entre o colonialismo, a guerra de libertação, a guerra de 1976 a 1992, até a assinatura do Acordo de Paz e os tempos atuais atualizam velhas formas de exploração da relação de trabalho é matéria para outra análise, no entanto, finalizamos esta com as palavras cortantes do feiticeiro de "Terra Sonâmbula", anunciando o futuro:

\begin{abstract}
Chorais pelos dias de hoje? Pois saibam que os dias que virão serão ainda piores. Foi por isso que fizeram essa guerra, para envenenar o ventre do tempo, para que o presente parisse monstros no lugar da esperança. [...] Porque esta guerra não foi feita para vos tirar do país mas para tirar o país de dentro de vós. Agora a arma é a vossa única alma. Roubaram-vos tanto que nem sequer os sonhos são vossos, nada de vossa terra vos pertence, e até o céu e o mar serão propriedade de estranhos. Será mil vezes pior que o passado pois não vereis o rosto dos novos donos e esses patrões se servirão de vossos irmãos para vos dar castigo. No final, porém, restará uma manhã como esta, cheia de luz nova e se escutará uma voz longínqua como se fosse uma memória de antes de sermos gente. E surgirão os doces acordes de uma canção, o terno embalo da primeira mãe (Couto, 1995, p. 241-242).
\end{abstract}

\title{
Referências
}

Althusser, Louis. Aparelhos ideológicos de Estado: notas sobre os aparelhos ideológicos do Estado (AIE). Rio de Janeiro: Graal, 1985.

Bettellheim, Bruno. A psicanálise dos contos de fada. Rio de Janeiro: Paz e Terra, 1980.

Bloch, Ernst. O princípio da esperança. Tradução de Nélio Schneider. Rio de Janeiro: Eduerj; Contraponto, 2005. v. 1

Couto, Mia. Terra sonâmbula. Rio de Janeiro: Nova Fronteira, 1995.

Diss, João. Godido e outros contos. Maputo: Associação dos Escritores Moçambicanos, 1988.

HonwanA, Luís Bernardo. Nós matamos o cão tinhoso. São Paulo: Ática, 1980.

MARx, Karl. O capital: crítica da economia política. Rio de Janeiro: Civilização Brasileira, s/d. v. 1. Marx, Karl; Engels, Friedrich. Manifesto do Partido Comunista. São Paulo, Global, 1986. 
Meneses, Maria Paula G. O “indígena” africano e o colono "europeu”: a construção da diferença por processos legais. Disponível em: <http://www.ces.uc.pt/myces/UserFiles/livros/693_04\%2520>. Acesso em: 20 mar. 2015.

Mondlane, Eduardo. Lutar por Moçambique. Maputo: Nosso Chão, [1967] 1995.

SouzA, Noêmia. Sangue negro. Maputo: Associação dos Escritores Moçambicanos, 2001.

Recebido em 19 de fevereiro de 2017.

Aprovado em 3 de março de 2017.

\section{Resumo/Abstract/Resumen}

\section{A representação do trabalho em João Dias e Luís Bernardo Honwana}

Rejane Vecchia da Rocha e Silva

Tatiane Reghini de Mattos

Este artigo apresenta, em perspectiva comparatista, uma análise de dois contos moçambicanos, "Godido”, de João Dias, e “As mãos dos pretos”, de Luís Bernardo Honwana, a partir, principalmente, da representação das condições de trabalho do negro dentro da estrutura colonial portuguesa do século xx em Moçambique.

Palavras-chave: João Dias, Luís Bernardo Honwana, literatura, força de trabalho, Moçambique.

\section{The representation of labour by João Dias and Luís Bernardo Honwana}

Rejane Vecchia da Rocha e Silva

Tatiane Reghini de Mattos

This paper presents an analysis of two Mozambican short stories, "Godido”, by João Dias, and "As mãos dos pretos", by Luís Bernardo Honwana, in a comparative perspective. It is based mainly on the representation of black working conditions in the Portuguese colonial structure of the $20^{\text {th }}$ Century in Mozambique.

Keywords: João Dias, Luís Bernardo Honwana, Mozambican literature, work force.

\section{La representación del trabajo en João Dias y Luís Bernardo Honwana}

Rejane Vecchia da Rocha e Silva

Tatiane Reghini de Mattos

Este artículo presenta, en una perspectiva comparativa, un análisis de dos cuentos mozambiqueños, “Godido”, de João Dias, y “As mãos dos pretos” de Luís Bernardo Honwana; a partir, principalmente, de la representación de las condiciones de trabajo del negro dentro de la estructura colonial portuguesa del siglo xx en Mozambique.

Palabras clave: João Dias, Luís Bernardo Honwana, Mozambique, literatura, fuerza de trabajo. 